\title{
An In Vitro Comparative Study to Assess Minimal Thickness Required for Monolithic Zirconia Crowns to Resist Fracture under Load on Rapid Prototyped Models
}

\author{
Vandana Narayanan ${ }^{1}$, Vinod Narayanan ${ }^{2}$, Shivkumar A Devanarayanan ${ }^{3}$
}

\begin{abstract}
Aim: To evaluate and validate minimal thickness required for computer-aided designed (CAD) and computer-aided manufactured (CAM) monolithic zirconia crowns to withstand occlusal load. The study compares two systems.

Materials and methods: Forty-eight rapid prototype die models with varying occlusal reductions were fabricated. Group I samples had an axial wall height of $7.0 \mathrm{~mm}$ with occlusal reduction of $0.5 \mathrm{~mm}$, group II had axial wall height $6.5 \mathrm{~mm}$ with occlusal reduction $1.0 \mathrm{~mm}$, group III had axial wall height $6.0 \mathrm{~mm}$ with occlusal reduction of $1.5 \mathrm{~mm}$. Control group IV had axial wall height $5.5 \mathrm{~mm}$ with occlusal reduction of $2.0 \mathrm{~mm}$. Laboratories A (Czar) and B (3M) were provided with 24 samples each, 6 samples in each group for fabricating CAD/CAM monolithic zirconia crowns of $0.5,1.0,1.5$, and $2 \mathrm{~mm}$ occlusal thickness, respectively, and cemented using resin-modified glass ionomer cement over the die models. Samples were loaded on a universal testing machine for fracture testing. Surface topography analysis of fractured specimens was done under the scanning electron microscope (SEM). The results were subjected to one-way analysis of variance (ANOVA) and honestly significant difference (HSD) Tukey test to analyze statistical significance at 0.05 levels.

Results: Samples of laboratory A performed superior to laboratory B. The $t$ test showed fracture resistance of group Al $(0.5 \mathrm{~mm})>\mathrm{group} \mathrm{BII}$ $(1.0 \mathrm{~mm})$ and also group Alll $(1.5 \mathrm{~mm})>$ control of Lab B $(2 \mathrm{~mm})$.

Conclusion: Monolithic zirconia crowns showed a favorable mechanical property to withstand occlusal load with minimal tooth preparation. The occlusal thickness of Czar with $0.5 \mathrm{~mm}$ is found to resist fracture under physiological masticatory load. Scanning electron microscope revealed increased voids in the microstructure of $3 \mathrm{M}$, which lead to decreased fracture resistance.

Clinical significance: Preservation of tooth structure can be considered using monolithic crowns with minimal thickness of $1 \mathrm{~mm}$.

Keywords: Fracture resistance, Monolithic crowns, Non-hot isostatic pressed zirconia block, Occlusal thickness, Rapid prototyping, Scanning electron microscope.

The Journal of Contemporary Dental Practice (2020): 10.5005/jp-journals-10024-2755
\end{abstract}

\section{INTRODUCTION}

The phenomenon of bond failure and esthetic drawbacks of porcelain fused to metal led to the invention of computer-aided designed (CAD) and computer-aided manufactured (CAM) metalfree restorative materials. An important advantage of poly-crystal ceramics like zirconia when compared to glass and particle-filled glass ceramics is their increased strength. The CAD/CAM technology enables complex shapes to be milled out of zirconia blanks where the prepared tooth is scanned and the crown is designed prior to milling. According to literature, the ideal tooth preparation for monolithic zirconia crown is $2 \mathrm{~mm}$ of occlusal clearance, $3-4 \mathrm{~mm}$ axial wall height, and a finish line of $0.5-1 \mathrm{~mm}$ chamfer. ${ }^{1-3}$ Teeth do not possess the regenerative ability found in most of other tissues. Therefore, careful attention to the amount of reduction is imperative during tooth preparation.

The objective of this study is to evaluate the minimum occlusal tooth reduction required for $\mathrm{CAD} / \mathrm{CAM}$ designed monolithic zirconia crowns of two systems (Czar, $3 \mathrm{M})$ to resist fracture. The null hypothesis of this study was that no difference was found in fracture resistance between the two systems.

\section{Materials and Methods} Scanning and Designing

An anatomical typodont first left mandibular molar tooth (NISSIN Dental Product Ltd, Japan) was scanned by contact probing

\begin{abstract}
1,30partment of Prosthodontics, Sri Ramakrishna Dental College and Hospital, Coimbatore, Tamil Nadu, India; The Tamil Nadu Dr MGR Medical University, Chennai, Tamil Nadu, India

${ }^{2}$ Department of Prosthodontics, Shirdi Dental Clinic, Coimbatore, Tamil Nadu, India

Corresponding Author: Vandana Narayanan, Department of Prosthodontics, Sri Ramakrishna Dental College and Hospital, Coimbatore, Tamil Nadu, India; The Tamil Nadu Dr MGR Medical University, Chennai, Tamil Nadu, India, Phone: +91 9495945676, e-mail: smiledentvand@gmail.com

How to cite this article: Narayanan V, Narayanan V, Devanarayanan SA. An In Vitro Comparative Study to Assess Minimal Thickness Required for Monolithic Zirconia Crowns to Resist Fracture under Load on Rapid Prototyped Models. J Contemp Dent Pract 2020;21(2):183-189.

Source of support: Nil

Conflict of interest: None
\end{abstract}

method (Renishaw SP620). Data were captured in the form of "cloud points" by TRACECUT software in less than a minute. This was converted to produce a three-dimensional image (3D; part modeling) with CATIA V5 software. The axial height of the scanned mandibular molar is $7.5 \mathrm{~mm}$, which is the height of a human mandibular first molar. ${ }^{4}$ The tooth preparation was designed in such a way that the proximal walls had a convergence of $6^{\circ}$ with $1.2 \mathrm{~mm}$ reduction in axial walls and margin of $1 \mathrm{~mm}$ deep chamfer (Fig. 1A).

(c) The Author(s). 2020 Open Access This article is distributed under the terms of the Creative Commons Attribution 4.0 International License (https://creativecommons. org/licenses/by-nc/4.0/), which permits unrestricted use, distribution, and non-commercial reproduction in any medium, provided you give appropriate credit to the original author(s) and the source, provide a link to the Creative Commons license, and indicate if changes were made. The Creative Commons Public Domain Dedication waiver (http://creativecommons.org/publicdomain/zero/1.0/) applies to the data made available in this article, unless otherwise stated. 


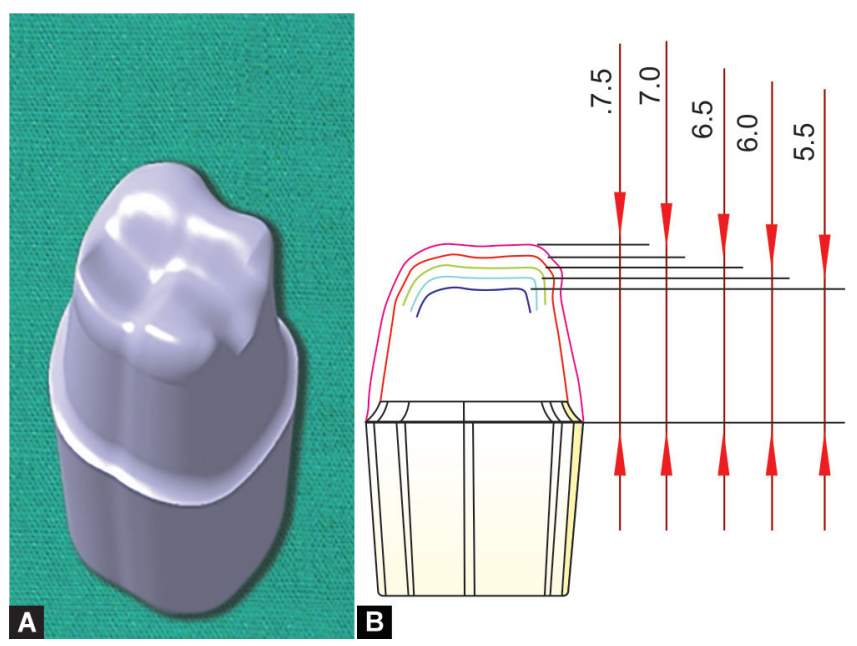

Figs $1 A$ and B: (A) Designing of virtual 3D tooth preparation model for rapid prototyping; (B) Diagrammatic representation of varying occlusal heights in millimeters

All the line angles were rounded. The final image of the virtual models was saved in standard template language file.

\section{Rapid Prototype Models}

A CAD file of the prepared mandibular molar tooth was imported to the rapid prototyping machine (Stratasys FORTUS 900mc, USA) for generating die models of mandibular molar teeth. To evaluate fracture resistance, a dimensionally stable standard die with the strength of nearing natural dentine $(69.9 \mathrm{MPa})^{5}$ is essential. Polyetherimide resin-ULTEM 9085 (Stratasys Ltd, UK) with the tensile strength of $71.6 \mathrm{MPa}$ was the material used (Fig. 2).

\section{Grouping}

From the virtual 3D model, 48 rapid first mandibular molar die models were generated. Twenty-four samples were grouped and sent to both the laboratories (laboratory A-Czar, laboratory $B-3 M)$ for fabrication of CAD/CAM monolithic zirconia crowns. Samples were grouped based on the occlusal reduction in the following manner (Fig. 1B):

- Group $\mathrm{Al}(n=6)$ had a crown height of $7.0 \mathrm{~mm}$ and occlusal reduction of $0.5 \mathrm{~mm}$.

- Group $\mathrm{BI}(n=6)$ had a crown height of $7.0 \mathrm{~mm}$ and occlusal reduction of $0.5 \mathrm{~mm}$.

- Group All $(n=6)$ had a crown height of $6.5 \mathrm{~mm}$ with occlusal reduction of $1.0 \mathrm{~mm}$.

- Group BII $(n=6)$ had a crown height of $6.5 \mathrm{~mm}$ with occlusal reduction of $1.0 \mathrm{~mm}$.

- Group Alll $(n=6)$ had a crown height of $6.0 \mathrm{~mm}$ with occlusal reduction of $1.5 \mathrm{~mm}$.

- Group BIII $(n=6)$ had a crown height of $6.0 \mathrm{~mm}$ with occlusal reduction of $1.5 \mathrm{~mm}$.

- Control group AIV $(n=6)$ had a crown height of $5.5 \mathrm{~mm}$ with occlusal reduction of $2.0 \mathrm{~mm}$.

- Control group BIV $(n=6)$ had a crown height of $5.5 \mathrm{~mm}$ with occlusal reduction of $2.0 \mathrm{~mm}$.

\section{Fabrication of CAD/CAM Monolithic Zirconia Crowns}

Contrast-sprayed die models were scanned at laboratory A (Czar) using Dental Wings series 5 (Dental Wings Inc., Canada) and

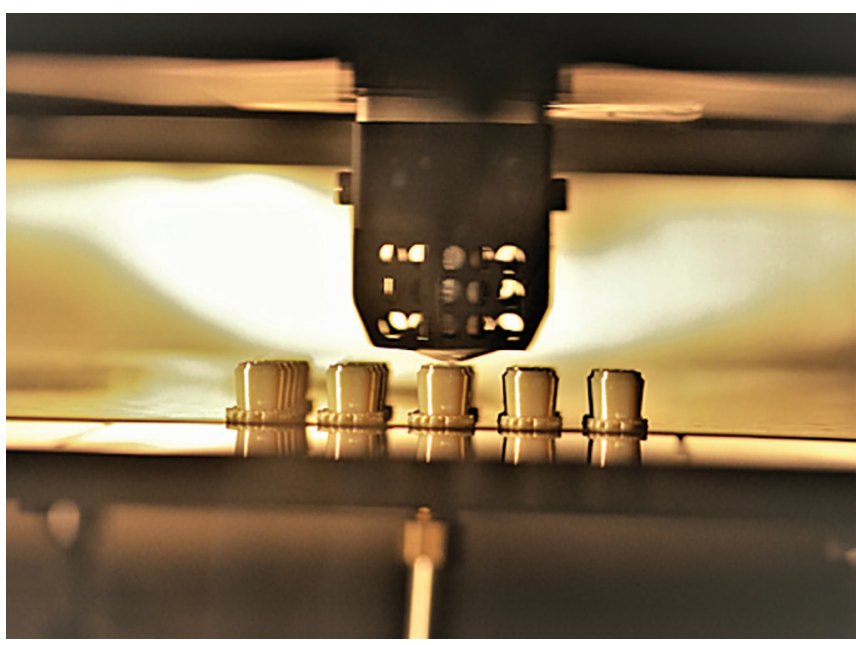

Fig. 2: Fabrication of rapid prototyped models

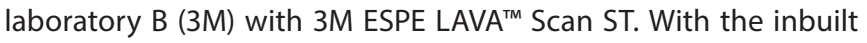
CAD software, the complete contour molar crowns of varying occlusal thicknesses of $0.5,1.0,1.5$, and $2.0 \mathrm{~mm}$ were designed for the respective die groups.

In laboratory A, milling process was performed with Yenadent D-40 milling unit (Yenadent Ltd, Istanbul, Turkey). Laboratory $B$ used LAVA ${ }^{\text {TM }}$ CNC 500 milling unit for milling zirconia blank. Non-hot isostatic pressed (HIPed) zirconia blocks were used. Crowns fabricated in laboratory A were sintered in Zirconofen 600/ V2 (Zircon Zahn, Atlanta) sintering machine at $1,500^{\circ} \mathrm{C}$ for 8 hours, and crowns of laboratory B were sintered in $3 \mathrm{M} \mathrm{LAVA}^{\mathrm{TM}}$ furnace 200 for 9 hours at $1,450^{\circ} \mathrm{C}$ according to the manufacturer.

The occlusal thickness was checked and cross verified by two Iwanson gauges. The fit of the crown was checked under a microscope at 50× magnification (Dewinter Technologies) for marginal fit. To increase the mechanical bonding for cementation, the intaglio surface of the crowns was sandblasted at 3 bars with $50 \mu$ aluminum oxide and then the crowns were rinsed and dried. Glazing was done with $\mathrm{A} 2$ stain on all 48 crowns at a temperature of $750^{\circ} \mathrm{C}$ in Programat 500 furnace (Ivoclar Vivadent, USA).

\section{Mounting of the Dies}

Ney's surveyor was used for axial alignment of the dies for mounting into the acrylic block. ${ }^{6}$ The sintered zirconia crowns were cemented using resin-modified glass ionomer cement (RelyX ${ }^{\mathrm{TM}} 3 \mathrm{M} / \mathrm{ESPE}, \mathrm{USA}$ ) onto their corresponding mounted dies. A custom-made cementing jig was used to ensure that the crown was loaded centrally during cementation at a force of $50 \mathrm{~N}$ for 10 minutes. ${ }^{7,8} \mathrm{~A} 2$ samples were stored in distilled water at room temperature for 24 hours to assure hydration and to simulate the oral environment. ${ }^{8}$

\section{Fracture Testing}

One layer of $1 \mathrm{~mm}$ thick polyethylene vacuum forming foil (EasyVac) was placed between the occlusal surface of the crown and the custom-made $6 \mathrm{~mm}$ diameter stainless steel piston to achieve a homogenous stress distribution. ${ }^{7}$ The samples were occlusally loaded, using a universal testing machine with a crosshead speed distribution of $1 \mathrm{~mm} /$ minute (INSTRON 3382, London, UK) (Fig. 3). Fracture was defined as the occurrence of visible cracks or chipping in combination with load drops and acoustic events (Fig. 4). The peak load was recorded for each sample. 


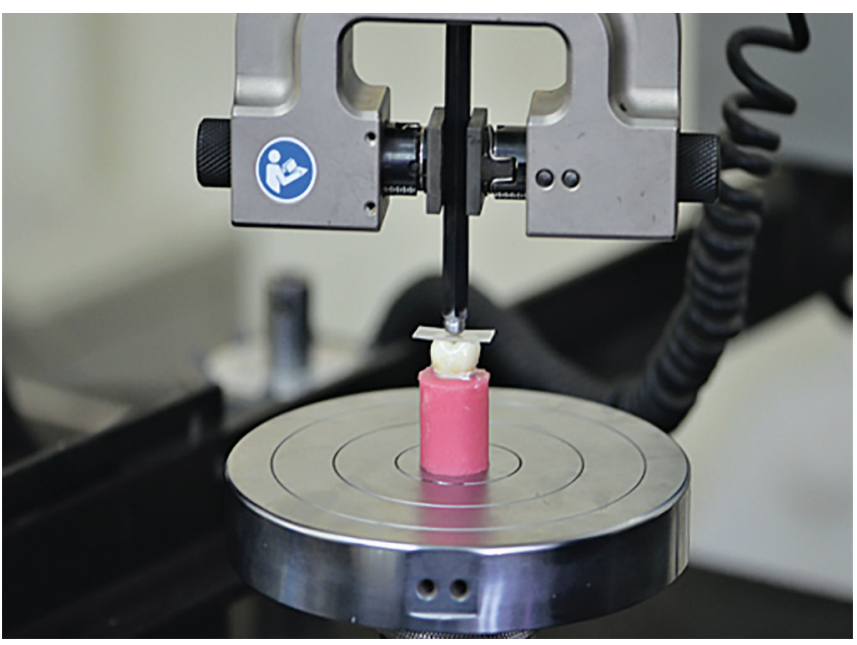

Fig. 3: Testing for fracture resistance under universal testing machine

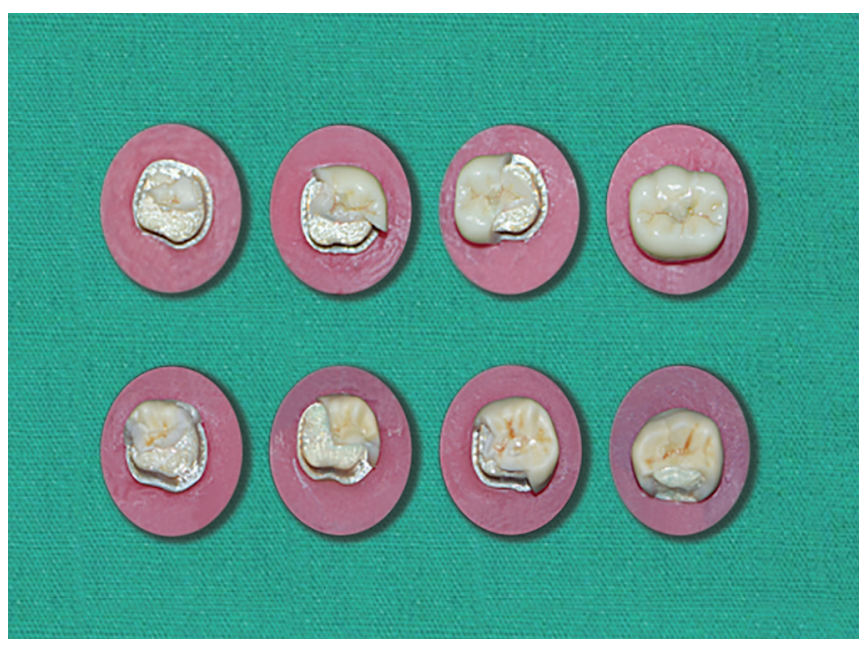

Fig. 4: Fractured specimens

Table 1: ANOVA and Tukey HSD tests fracture strength of zirconia crowns-Czar laboratory A

\begin{tabular}{llrrrrr}
\hline System & & Sum of squares & $d f$ & Mean square & $F$ & $p$ value \\
\hline Czar & Between groups & 49953810.906 & 3 & 16651270.302 & 187.468 & 0.000 \\
& Within groups & 1776439.139 & 20 & 88821.957 & & \\
& Total & 51730250.045 & 23 & & & \\
\hline
\end{tabular}

Dependent variable: fracture strength of zirconia crowns

\begin{tabular}{|c|c|c|c|c|c|}
\hline \multicolumn{6}{|c|}{ Multiple comparisons } \\
\hline System & (I) thickness & (J) thickness & Mean difference $(I-J)$ & Std. error & $p$ value \\
\hline \multirow[t]{12}{*}{ Czar } & Control $(2 \mathrm{~mm})$ & Alll $1.5 \mathrm{~mm}$ & $1549.2067(*)$ & 172.06777 & 0.000 \\
\hline & & All $1.0 \mathrm{~mm}$ & $2828.4067\left(^{*}\right)$ & 172.06777 & 0.000 \\
\hline & & Al $0.5 \mathrm{~mm}$ & $3857.4100(*)$ & 172.06777 & 0.000 \\
\hline & Alll $(1.5 \mathrm{~mm})$ & Control & $-1549.2067\left(^{*}\right)$ & 172.06777 & 0.000 \\
\hline & & All $1.0 \mathrm{~mm}$ & $1279.2000(*)$ & 172.06777 & 0.000 \\
\hline & & Alll $0.5 \mathrm{~mm}$ & $2308.2033\left(^{*}\right)$ & 172.06777 & 0.000 \\
\hline & All $(1.0 \mathrm{~mm})$ & Control & $-2828.4067(*)$ & 172.06777 & 0.000 \\
\hline & & Alll $1.5 \mathrm{~mm}$ & $-1279.2000(*)$ & 172.06777 & 0.000 \\
\hline & & Al $0.5 \mathrm{~mm}$ & $1029.0033(*)$ & 172.06777 & 0.000 \\
\hline & $\mathrm{Al}(0.5 \mathrm{~mm})$ & Control & $-3857.4100(*)$ & 172.06777 & 0.000 \\
\hline & & Alll $1.5 \mathrm{~mm}$ & $-2308.2033(*)$ & 172.06777 & 0.000 \\
\hline & & All $1.0 \mathrm{~mm}$ & $-1029.0033\left(^{*}\right)$ & 172.06777 & 0.000 \\
\hline
\end{tabular}

*The mean difference is significant at the 0.05 level

\section{Scanning Electron Microscope}

The fractured specimens were gold sputtered (Quarum, Q150RSEngland) for 120 seconds to visualize the surface topography of the fractured crowns under SEM. Scanning electron microscope was used to observe the reason for crack propagation (Carl Zeiss, Germany).

\section{Statistical Analysis}

The data so obtained were compiled systematically and subjected to statistical analysis using ANOVA and Tukey's test. Student's $t$ test was used to analyze the variation between the groups.

\section{Results}

- As the thickness increased, the fracture resistance of laboratory A material also increased, with highest fracture resistance for the control group (5337.8250 N), followed by group All (3788.6183 $\mathrm{N})$, All $(2509.4183 \mathrm{~N})$, and Al (1480.4150 N).

- As the thickness increased, the mean fracture resistance of laboratory B material also increased with highest fracture resistance for the control group (3899.4433 N), followed by group BIII (3218.2900 N), BII (1768.3633 N), and BI (951.5133 N).

Both ANOVA and Tukey's HSD (post hoc) (Tables 1 and 2) were employed to compare the groups pairwise based on mean values since $p$ value was less than 0.05 (5\% level of significance), and the null hypothesis was proven wrong. The test favored the alternative hypothesis that a significant difference was observed in fracture resistance of laboratory A (Czar) and laboratory B (3M) monolithic zirconia crowns fabricated with various thickness. Table 3 and Figure 5 show that the fracture resistance of laboratory A performs better than that of laboratory $\mathrm{B}$. 
Study to Assess Thickness of Monolithic Zirconia Crowns to Resist Fracture

Table 2: ANOVA and Tukey HSD tests fracture strength of zirconia crowns-3M laboratory B

\begin{tabular}{|c|c|c|c|c|c|c|}
\hline System & & Sum of squares & $d f$ & Mean square & $F$ & $p$ value \\
\hline \multirow[t]{3}{*}{$3 \mathrm{M}$} & Between groups & 32405356.249 & 3 & 10801785.416 & 149.910 & 0.000 \\
\hline & Within groups & 1441099.470 & 20 & 72054.974 & & \\
\hline & Total & 33846455.719 & 23 & & & \\
\hline \multicolumn{7}{|c|}{ Dependent variable: fracture strength of zirconia crowns } \\
\hline \multicolumn{7}{|c|}{ Multiple comparisons } \\
\hline System & (I) thickness & (J) thickness & Mean difference (I & $(I-J)$ & Std. error & $p$ value \\
\hline \multirow[t]{12}{*}{$3 \mathrm{M}$} & Control (2 mm) & $1.5 \mathrm{~mm}$ & $681.1533\left(^{*}\right)$ & & 154.97846 & 0.001 \\
\hline & & $1.0 \mathrm{~mm}$ & $2131.0800\left(^{*}\right)$ & & 154.97846 & 0.000 \\
\hline & & $0.5 \mathrm{~mm}$ & $2947.9300\left(^{*}\right)$ & & 154.97846 & 0.000 \\
\hline & BIII (1.5 mm) & Control & $-681.1533\left(^{*}\right)$ & & 154.97846 & 0.001 \\
\hline & & $1.0 \mathrm{~mm}$ & $1449.9267\left(^{*}\right)$ & & 154.97846 & 0.000 \\
\hline & & $0.5 \mathrm{~mm}$ & $2266.7767\left(^{*}\right)$ & & 154.97846 & 0.000 \\
\hline & BII (1.0 mm) & Control & $-2131.0800\left(^{*}\right)$ & & 154.97846 & 0.000 \\
\hline & & $1.5 \mathrm{~mm}$ & $-1449.9267\left(^{*}\right)$ & & 154.97846 & 0.000 \\
\hline & & $0.5 \mathrm{~mm}$ & $816.8500\left(^{*}\right)$ & & 154.97846 & 0.000 \\
\hline & $\mathrm{BI}(0.5 \mathrm{~mm})$ & Control & $-2947.9300\left(^{*}\right)$ & & 154.97846 & 0.000 \\
\hline & & $1.5 \mathrm{~mm}$ & $-2266.7767\left(^{*}\right)$ & & 154.97846 & 0.000 \\
\hline & & $1.0 \mathrm{~mm}$ & $-816.8500\left(^{*}\right)$ & & 154.97846 & 0.000 \\
\hline
\end{tabular}

*The mean difference is significant at the 0.05 level

Table 3: Comparison between the mean fracture resistances of two systems

\begin{tabular}{lll}
\hline & \multicolumn{2}{c}{ System } \\
\cline { 2 - 3 } & Czar laboratory A & 3M laboratory B \\
\cline { 2 - 3 } Thickness & $\begin{array}{l}\text { Fracture strength of } \\
\text { zirconia crowns }(n)\end{array}$ & $\begin{array}{l}\text { Fracture strength of } \\
\text { zirconia crowns }(n)\end{array}$ \\
\hline Control & 5337.8250 & 3899.4433 \\
$1.5 \mathrm{~mm}$ & 3788.6183 & 3218.2900 \\
$1.0 \mathrm{~mm}$ & 2509.4183 & 1768.3633 \\
$0.5 \mathrm{~mm}$ & 1480.4150 & 951.5133 \\
\hline
\end{tabular}

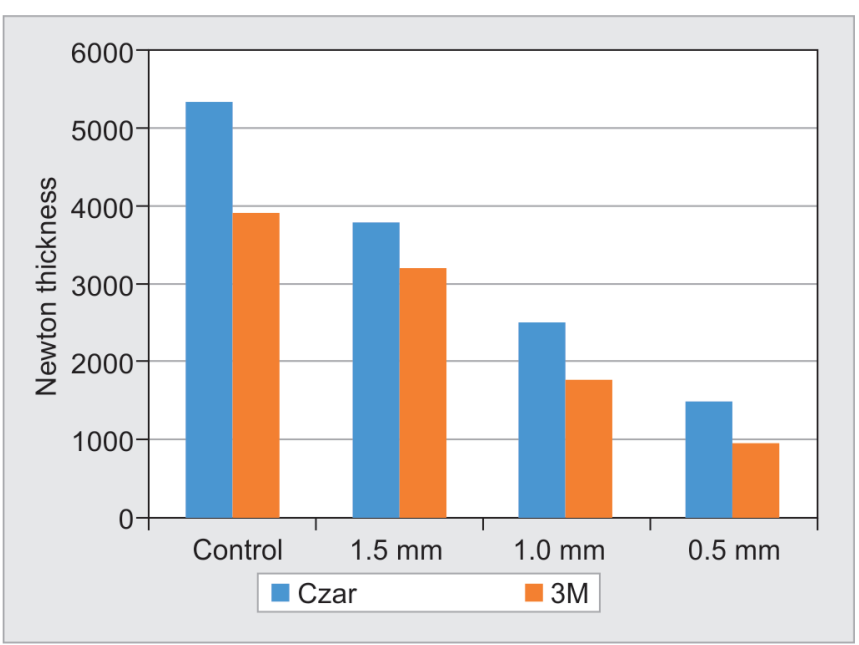

Fig. 5: Graphical representation between the two systems

The $t$ test (Table 4) inferred that the fracture resistance of 0.5 mm occlusal thickness of laboratory A (1480.415 N) and $1 \mathrm{~mm}$ of laboratory $\mathrm{B}(1768.363 \mathrm{~N})$ were compared an insignificant difference ( $p$ value is $>0.05$ ) was observed. Similarly $1.5 \mathrm{~mm}$ of laboratory
A $(3788.618 \mathrm{~N})$ to the control $2 \mathrm{~mm}$ of laboratory B $(3899.443 \mathrm{~N})$ also showed insignificant difference (since $p$ value is $>0.05$ ), which indicates that the fracture resistance of laboratory A (Czar) at lower occlusal thickness is greater than the occlusal thickness of laboratory B (3M).

\section{Discussion}

In this study, the ideal cervico occlusal length of $7.5 \mathrm{~mm}$ was considered for first left mandibular crown as given by Ash and Nelson. ${ }^{4}$ To standardize the molar tooth anatomy, a typodont tooth was scanned and the 3D virtual model designing was performed. The tooth preparation in the present study was designed by CAD software in accordance with the previous studies, ${ }^{9,10}$ such that the proximal walls each had $6^{\circ}$ taper and the axial walls were reduced by $1.2 \mathrm{~mm}$. Bonfante ${ }^{11}$ stated that fracture resistance of chamfer margin was more than shoulder margin because the chamfer margin has a curve and round internal angle which leads to more marginal fit and spreads the load better. So the finish line of the virtual model was designed with $1 \mathrm{~mm}$ deep chamfer and all the line angles were rounded.

Restoring the mandibular first molar was considered because the maximum biting force $(300-600 \mathrm{~N})$ in natural dentition is in the first molar region. ${ }^{3,12,13}$ Braun et al. ${ }^{14}$ and Hylander ${ }^{15}$ measured $1,000 \mathrm{~N}$ as the critical load on the first molar during the normal human oral function. In a study conducted by Hattori et al., ${ }^{16}$ the magnitude of the bite force varied from 246.9 to $2091.9 \mathrm{~N}$, with a median of $776.7 \mathrm{~N}$. It has been reported by Waltimo et al. ${ }^{17}$ that patients with bruxism or clenching exert a supraphysiological force on their teeth. Such patients have an increased possibility of crown fracture. Waugh ${ }^{18}$ reported clenching forces up to $1547 \mathrm{~N}$ (348 lbs) in the Alaskan Eskimo. A world record clenching force of $4333 \mathrm{~N}$ (975 Ibs) was recorded for a man with a clenching habit. ${ }^{19}$

A study by Yucel et al. ${ }^{20}$ suggests that the modulus of elasticity of the supporting die structure may have a significant effect on the 
Table 4: $t$ test comparison between Czar and 3M

\begin{tabular}{llrrrrc}
\hline & & \multicolumn{4}{c}{ 3M laboratory B } \\
\cline { 3 - 6 }$p$ values (t test) & & Control B & BIII 1.5 mm & BII 1 mm & BI 0.5 mm & Mean $n($ Czar) \\
\hline Czar laboratory A & Control A & 0.000 & 0.000 & 0.000 & 0.000 & 5337.825 \\
& Alll $1.5 \mathrm{~mm}$ & $\mathbf{0 . 3 8 6}$ & 0.003 & 0.000 & 0.000 & $\mathbf{3 7 8 8 . 6 1 8}$ \\
& All $1 \mathrm{~mm}$ & 0.000 & 0.006 & 0.004 & 0.000 & 2509.418 \\
& Al $0.5 \mathrm{~mm}$ & 0.000 & 0.000 & $\mathbf{0 . 1 6 0}$ & 0.012 & $\mathbf{1 4 8 0 . 4 1 5}$ \\
\hline
\end{tabular}
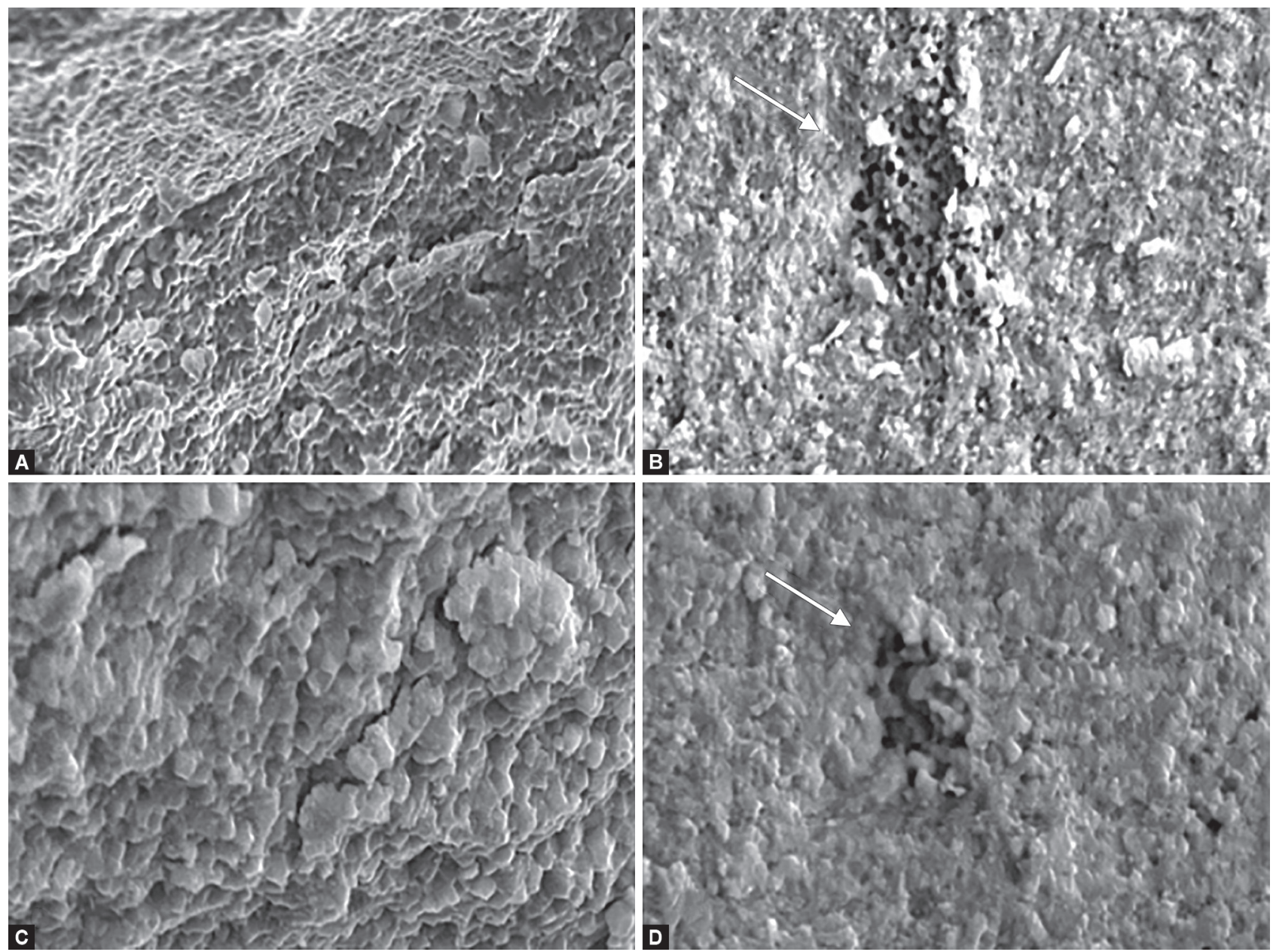

Figs 6A to D: (A) SEM micrograph of laboratory A specimen shows absence of voids (10.53 KX); (B) SEM micrograph of laboratory B specimen shows cluster of multiple voids (10.64 KX); (C) SEM micrograph of laboratory A specimen shows absence of voids (18 KX); (D) SEM micrograph of laboratory B specimen shows cluster of multiple voids (18 KX)

ability of the model to accurately reflect the clinical conditions. To obtain realistic fracture strength values, materials with a modulus of elasticity closer to human dentine must be used rather than a metal die. Inoue et al. ${ }^{21}$ reported tensile strength of mineralized dentine ranged $99.8 \pm 27.9 \mathrm{MPa}$ when loaded perpendicular to the tubule axis. Nishitani et al. ${ }^{5}$ stated that the elastic modulus of normal dentine is $69.9 \mathrm{MPa}$. Standardization of die models was done by rapid prototyping of ULTEM (ISO10993, FDA) material as the modulus of elasticity (71.6 MPa) was closer to human dentine.

Langeland ${ }^{22}$ stated that full crown preparation with diamond points at ultra-high speed cannot be carried out without causing some trauma to the dentine and pulp. Hence, it is important to implement conservative preparation of the tooth, so that minimum thickness of the crown can withstand masticatory load. From a wide array of tooth-colored materials available for full coverage, zirconia is the latest and strongest material. Zirconia has flexural strength ranging from 900 to $1,200 \mathrm{MPa}^{23}$ and compressive strength of $2,000 \mathrm{MPa}^{24}$ But the minimum thickness required for monolithic zirconia crown to withstand occlusal load needs to be analyzed and identified, so as to clinically perform minimal tooth reduction.

This in vitro study was aimed at comparing the fracture resistance of two monolithic zirconia crown materials with an occlusal thickness of $0.5,1.0,1.5$, and $2.0 \mathrm{~mm}$. Both systems used the same manufacturing protocol with non-HIPed zirconia blocks. Conventional glass ionomer cement has low tensile strength and fracture toughness, and they are susceptible to attack by moisture 
during the initial setting period ${ }^{25-27}$ and hence resin-modified glass ionomer cement with a molecular bonding ability was used in the study. During fracture testing, a layer of $1 \mathrm{~mm}$ thickness polyethylene vacuum-forming foil was placed between the occlusal surface of the crown and the piston to achieve a homogenous stress distribution. ${ }^{7}$ Soares et al. ${ }^{6}$ in his study concluded that periodontal ligament simulation has a greater influence on the fracture direction rather than on the fracture load values. Hence, in this study no periodontal ligaments (PDL) simulation was done and the specimens were mounted in acrylic, representing alveolar bone. Specimens with $2 \mathrm{~mm}$ thickness crowns were taken as the control group. ${ }^{28}$

This study evaluated the fracture resistance under static load. The mean fracture strength of the two manufacturers showed that laboratory A (Czar) had better fracture resistance when compared to laboratory $B(3 \mathrm{M})$. As the thickness of the crown increased, the fracture resistance to load also increased.

To the question, what is the minimum thickness required for the monolithic zirconia crown for withstanding the occlusal load, the answer that can be inferred within the limitations of this study is as follows:

- While considering the previous studies on masticatory load, the mean limit of fracture resistance for a posterior restorative material to survive clinically can be set at $1,000 \mathrm{~N} .^{15,16}$

- Considering that Al of Czar with $0.5 \mathrm{~mm}$ occlusal thickness $(1480.4150 \mathrm{~N})$ is adequate to take up the normal occlusal load but there is a high risk of fracture for $\mathrm{BI}$ of $3 \mathrm{M}(951.5133 \mathrm{~N})$ since its mean fracture resistance is below the mean masticatory load.

- For patients with bruxism, greater occlusal thickness of zirconia crowns is indicated. In this situation, a minimal requirement can be accomplished with All $(1.0 \mathrm{~mm})$ as its fracture resistance is 2509.41 N and group Bll with 1768.36 N, which is higher to the mean clenching force $(1,547 \mathrm{~N})$ reported in Bruxers. ${ }^{18}$

In this study, the fracture resistance of laboratory $A$ was significantly different from laboratory $B$ ( $p$ value is less than 0.05 ). Hence, the fractured specimens were further studied under SEM for surface topography analysis. At greater magnification, the $3 \mathrm{M}$ specimens showed multiple voids near the fracture line. This could be one of the reasons for its decreased strength when compared to Czar (Fig. 6).

It is necessary to specify that the testing in this study was performed under static load. Intraorally, teeth are subjected to multiple loading and varying thermal environment during mastication and hence further mouth motion fatigue testing can be explored to closely simulate clinical condition. Further study can be performed with resin cement to evaluate whether the cement causes any characteristic change in the mechanical property and the type of fracture of the monolithic zirconia crowns.

\section{Conclusion}

Within the limitations of this study, the following conclusion can be drawn:

- Monolithic zirconia crown shows a favorable mechanical property to withstand posterior occlusal load with minimal tooth preparation.

- Occlusal thickness of $0.5 \mathrm{~mm}$ Czar is found to resist fracture under physiological masticatory load.

- Monolithic zirconia crown of $1 \mathrm{~mm}$ and above occlusal thickness should be considered for patients with parafunctional habit.

\section{References}

1. Blair FM, Wassell RW, Steele JG. Crowns and other extra-coronal restorations: preparations for full veneer crowns. Br Dent J 2002;192(10):561-564. DOI: 10.1038/sj.bdj.4801428.

2. Zarone F, Russo S, Sorrentino R. From porcelain-fused-to-metal to zirconia: clinical and experimental considerations. Dent Mater 2011;27(1):83-96. DOI: 10.1016/j.dental.2010.10.024.

3. Shinogaya $T$, Bakke $M$, Thomsen $C E$, et al. Bite force and occlusal load in healthy young subjects-a methodological study. Eur J Prosthodont Restor Dent 2000;8(1):11-15.

4. Ash MM, Nelson SJ. Wheeler's Dental Anatomy, Physiology, and Occlusion, 8th ed. Saunders; 2006. p. 302.

5. Nishitani Y, Yoshiyama M, Tay FR. Tensile strength of mineralized/ demineralized human normal and carious dentin. J Dent Res 2005;84(11):1075-1078. DOI: 10.1177/154405910508401121.

6. Soares CJ, Pizi EC, Fonseca RB, et al. Influence of root embedment material and periodontal ligament simulation on fracture resistance tests. Braz Oral Res 2005;19(1):11-16. DOI: 10.1590/S180683242005000100003.

7. Beuer F, Schweiger J, Eichberger M. High-strength CAD/CAMfabricated veneering material sintered to zirconia copings-a new fabrication mode for all-ceramic restorations. Dent Mater 2009;25(1):121-128. DOI: 10.1016/j.dental.2008.04.019.

8. Ersu B, Narin D, Aktas G, et al. Effect of preparation taper and height on strength and retention of zirconia crowns. Int J Prosthodont 2012;25(6):582-584.

9. Goodacre CJ, Campagni WV, Aquilino SA. Tooth preparations for complete crowns: an art form based on scientific principles.J Prosthet Dent 2001;85(4):363-376. DOI: 10.1067/mpr.2001.114685.

10. Giannetopoulos $S$, van Noort R. Evaluation of the marginal integrity of ceramic copings with different marginal angles using two different CAD/CAM systems. J Dent 2010;38(12):980-986. DOI: 10.1016/ j.jdent.2010.08.011.

11. Bonfante EA, Coelho PG, Guess PC, et al. Fatigue and damage accumulation of veneer porcelain pressed on Y-TZP. J Dent 2010;38(4):318-324. DOI: 10.1016/j.jdent.2009.12.004.

12. Bakke $M$, Michler $L$, Han $K$, et al. Clinical significance of isometric bite force versus electrical activity in temporal and masseter muscles. Scand J Dent Res 1989;97(6):539-551. DOI: 10.1111/j.1600-0722.1989. tb00929.x.

13. Hagberg C. Assessments of bite force: a review. J Craniomandib Disord 1987;1(3):162-169.

14. Braun S, Bantleon HP, Hnat WP, et al. A study of bite force, part 1: relationship to various physical characteristics. Angle Orthod 1995;65(5):367-372. DOI: 10.1043/0003-3219(1995)065<0367:ASOB $\mathrm{FP}>2.0 . \mathrm{CO} ; 2$.

15. Hylander WL. The adaptive significance of Eskimo craniofacial morphology. In: Dahlberg AA, Graber TM, ed. Orofacial Growth and Development. The Hague: Mouton Publishers; 1977. pp. 129-169.

16. Hattori $Y$, Satoh C, Kunieda T. Bite forces and their resultants during forceful inter-cuspal clenching in humans. J Biomech 2009;42(10):1533-1538. DOI: 10.1016/j.jbiomech.2009.03.040.

17. Waltimo A, Nystrom M, Kononen M. Bite force and dentofacial morphology in men with severe dental attrition. Scand J Dent Res 1994;102(2):92-96. DOI: 10.1111/j.1600-0722.1994.tb01161.x.

18. Waugh LM. Dental observations among Eskimo. VII. Survey of mouth conditions, nutritional study, and gnatho - dynamometer data, in most primitive and populous native villages in Alaska. J Dent Res 1937;16:355-356.

19. Gibbs $\mathrm{CH}$, Mahan PE, Mauderli A, et al. Limits of human bite strength.J Prosthet Dent 1986;56(2):226-229. DOI: 10.1016/0022-3913(86)904804.

20. Yucel MT, Yondem I, Aykent F, et al. Influence of the supporting die structures on the fracture strength of all-ceramic materials. Clin Oral Invest 2012;16(4):1105-1110. DOI: 10.1007/s00784-011-0606-z.

21. Inoue S, Pereira PN, Kawamoto $C$, et al. Effect of depth and tubule direction on ultimate tensile strength of human coronal dentin. Dent Mater J 2003;22(1):39-47. DOI: 10.4012/dmj.22.39. 
22. Langeland K, Langeland LK. Pulp reactions to crown preparation, impression, temporary crown fixation and permanent cementation. J Prosthet Dent 1965;15:129-143. DOI: 10.1016/0022-3913(65) 90073-9.

23. Denry I, Kelly J. State of the art zirconia for dental applications. Dent Mater 2008;24(3):299-307. DOI: 10.1016/j.dental.2007. 05.007.

24. Piconi C, Maccauro G. Zirconia as a ceramic biomaterial. Biomaterials 1999;20(1):1-25. DOI: 10.1016/S0142-9612(98)00010-6.
25. Cho E, Kopel H, White SN. Moisture susceptibility of resin-modified glass ionomer materials. Quintessence Int 1995;26(5):351-358.

26. Gemalmaz D, Yoruc AB, Ozcan M, et al. The effect of early water contact on solubility of glass ionomer cements. J Dent Res 1997;76:318.

27. Mojon P, Kaltio R, Feduik D, et al. Short-term contamination of luting cements by water and saliva. Dent Mater 1996;12(2):83-87. DOI: 10.1016/S0109-5641(96)80073-X.

28. Shillingburg HT, Hobo S, Whitsett LD, et al. Fundamentals of Fixed Prosthodontics, 3rd ed. Quintessence Publication Co. Inc.; 2002. 